\title{
Diet intervention and ADHD symptoms with reference to gender, socio-economic status and area of residence
}

See end of the paper for authors' affiliations

\section{G.K. BEELA}

Centre for Disability Studies,

Poojapura,

THIRUVANANTHAPURAM,

(KERALA) INDIA

Email : beela.gk@kau.in
ABSTRACT : This study is intended to provide a comprehensive overview of the role of diet intervention on the behaviour of a random group of male and female School going Children of different socio-economic status and area of residence who meet the DSM IV criteria for ADHD. Though there is a wealth of research studies on the association of diet and supplements with the ADHD symptoms, there has been minimal empirical research in India charecterising dietary intervention with gender, socio-economic status and area of residence. The present study was carried out with a questionnaire consisting of 25 questions in the form of five scale rating which was administered to the subjects in six sessions to determine the prevalence of ADHD symptoms during the diet intervention. School going children of age group of 4-12 years were assessed for ADHD symptoms using DSM IV criteria. Forty one male and nine females with ADHD symptoms were selected for the diet intervention study. This current pre post study establishes that elimination of chocolates, Maida, bakery confectionaries, soft drinks, and junk food in the diet and replacing with highly nutritive value foods as per the RDA can reduce the ADHD symptoms. The study also revealed that gender, socio-economic status or the area of residence doesnt play any role in the diet intervention of ADHD children though the prevalance of ADHD is more seen in the males.

KEY WORDS: ADHD - Attention deficit hyperactivity disorder, Diet intervention, Food elimination, School going children, DSM IV criteria

- HOW TO CITE THIS PAPER : Beela, G.K. and Raji, V.R. (2016). Diet intervention and ADHD symptoms with reference to gender, socio-economic status and area of residence. Asian J. Home Sci., 11 (1) : 111-116, DOI: 10.15740/HAS/AJHS/11.1/111-116. 